\title{
Increasing Proactive Coping in Organizational Newcomers: Improving Job Adaptation or Rocking the Boat?
}

Journal of Career Development 2019, Vol. 46(3) 295-3I3

(C) Curators of the University of Missouri 2018

Article reuse guidelines: sagepub.com/journals-permissions DOI: $10.1177 / 0894845318763947$ journals.sagepub.com/home/jcd

@SAGE

\author{
Katarzyna Ślebarska', Roman Soucek ${ }^{2}$, and Klaus Moser ${ }^{2}$
}

\begin{abstract}
Proactivity has positive effects for the adaptation to the workplace. This study introduces an intervention that aims to enhance one important resource of newcomer adaptation, proactive coping, by a resource accumulation and controllability intervention for organizational newcomers. The effectiveness of the intervention (a structured booklet) was assessed in a sample of organizational newcomers $(N=172)$ within a longitudinal evaluation design (one-pretest double-posttest design with a treatment and a control group). The intervention improved proactive coping and enhanced an important proximal adaptation outcome, role clarity (mediated by proactive coping). However, the intervention also increased intention to quit especially among those newcomers who had previous job experience (i.e., job changers). Overall, the study demonstrates that increasing proactive coping improves the adaptation of organizational newcomers with respect to role clarity and therefore provides a promising starting point for additional intervention programs but also demonstrates limits of such an intervention.
\end{abstract}

\section{Keywords}

proactive coping, job adaptation, role clarity, intention to quit, organizational newcomers

These days, career paths are much less linear and bound to a specific organization than in earlier times. According to the U.S. Bureau of Labor Statistics (2015), persons born in the years 1957-1964 held 11.7 jobs from age 18 to 48 . Although job mobility is lower in Europe compared to the United States, interstate mobility in Europe is increasing slowly from a low level (Krieger, 2010). Individuals are increasingly mobile, and therefore improving newcomer adaptation becomes a major task for human resource management.

\footnotetext{
I Institute of Psychology, University of Silesia in Katowice, Katowice, Poland

${ }^{2}$ Department of Organizational and Social Psychology, Friedrich-Alexander University Erlangen-Nürnberg, Nuremberg, Germany
}

\section{Corresponding Author:}

Roman Soucek, Department of Organizational and Social Psychology, Friedrich-Alexander University Erlangen-Nürnberg, Lange Gasse 20, 90403 Nuremberg, Germany.

Email: roman.soucek@fau.de 
Organizational socialization tactics can be viewed as an important starting point in this endeavor and have positive effects on work performance and retention of employees (Bauer, Bodner, Erdogan, Truxillo, \& Tucker, 2007). Previous research on organizational socialization mainly focused on socialization tactics initiated by the organization; however, recently, there has been increasing interest in proactive behaviors of organizational newcomers (Gruman \& Saks, 2011). Saks, Gruman, and Cooper-Thomas (2011) described newcomer proactivity as "the means by which newcomers actively engage with their work environment through proactive socialization strategies such as seeking information about their role and work environment to reduce uncertainty" (p. 36). Recent research provided evidence that such newcomer proactive behaviors are associated with positive socialization outcomes including learning, social integration, and a lower intention to leave (Ashforth, Sluss, \& Saks, 2007; Saks, Gruman, \& Cooper-Thomas, 2011). Given the importance of proactive behavior, Gruman and Saks (2011) emphasized the need to test the effectiveness of proactive behavior interventions on newcomers' socialization outcomes.

Organizational entry can be conceptualized as a critical period that is associated with specific and high demands, such as uncertainty concerning relationships and tasks and so on (Reicherts \& Pihet, 2000). Therefore, Saks and Gruman (2012) argued that understanding socialization from a stressoriented perspective is important. Ellis et al. (2015) also called for a stress-based view on socialization and proposed that resources contribute to the socialization process because they provide means for coping with the challenges of organizational entry. Searle and Lee (2015) introduced proactive coping as a personal resource in an expanded job demands-resources model (Demerouti, Bakker, Nachreiner, \& Schaufeli, 2001) and argued that "proactive coping ought to be a particularly effective strategy for managing work demands" (p. 417). Within the framework of the job demands-resources model, proactive coping partially mediates the relationship between job demands and burnout as well as between job resources and engagement (Ângelo \& Chambel, 2012; see also Greenglass \& Fiskenbaum, 2009).

Following both a stress-oriented perspective on organizational socialization (Ellis et al., 2015) and the call of Gruman and Saks (2011) for interventions that foster a proactive orientation, we present an intervention to enhancing proactive coping of organizational newcomers, and we assess its effectiveness. We expect that fostering proactive coping should result in organizational adaptation, and therefore we address proximal and distal socialization outcomes, namely, an increase in role clarity and reduction of intention to quit (Ellis et al., 2015; Wanberg, 1997). Moreover, existing research has indicated that pre-entrance experiences might have an influence on socialization (e.g., Stephens \& Dailey, 2012). We therefore compare the effectiveness of the intervention and proactive coping between those previously unemployed and job changers. This is an especially valuable distinction because there is a lack of evidence concerning the adaptation to a new workplace of those previously unemployed; in studies on the success of reemployment, the criteria are mainly limited to the number of job interviews and time to reemployment (e.g., Van Hooft \& Noordzij, 2009).

\section{Proactive Coping}

Proactive coping is a specific form of problem-focused coping in which people take action in order to prevent stressful events (Aspinwall \& Taylor, 1997) or to better cope with future stressors (Schwarzer $\&$ Taubert, 2002). The notion of proactive coping differs from the traditional understanding of coping (Greenglass, 2002; Schwarzer \& Taubert, 2002). Whereas coping, in general, is oriented toward the compensation of loss or harm in the past, or more generally, how to deal with a stressor that already occurred, proactive coping aims to prepare the individual in such a way that stressors either should not occur at all or should be limited in their effect by means of, for example, strengthening the individual's capabilities for managing or even changing the situation in advance (Drummond \& Brough, 2016). According to Searle and Lee (2015), proactive coping is a resource at work, and activities such as anticipation, goal setting, planning, and reflection are important components of proactive coping. 
We suggest integrating these two approaches and assume that an individual who proactively copes effectively is able to accumulate different resources and skills that facilitate the prevention or management of stressors and can control — or at least believes in being able to control — future incidences. In sum, proactive coping helps to deal with both already existing demands (Searle \& Lee, 2015) and potential future stressors (Aspinwall \& Taylor, 1997) by (1) accumulating resources and (2) trying to gain and maintain control of one's environment.

\section{Enhancing Proactive Coping}

As entering a new organization is a considerable source of stress (Ellis et al., 2015), increasing proactive coping strategies is a promising candidate for improving the socialization of organizational newcomers (Greenglass \& Fiskenbaum, 2009; Searle \& Lee, 2015). Effective interventions on proactive coping have been successfully developed and implemented in different contexts, for example, preparation of aging (Bode, de Ridder, Kuijer, \& Bensing, 2007) or self-care behaviors (Thoolen, de Ridder, Bensing, Gorter, \& Rutten, 2007). Refining the conceptualization of proactive coping, Sohl and Moyer (2009) concluded that interventions aiming at the enhancement of proactive coping "should focus on promoting resources and realistic goal setting" (p. 143).

In the following, we explain how proactive coping might be enhanced in organizational newcomers. Especially, interventions, such as training, coaching, or booklets, should aim at raising (a) the individual's resources (cf. resource accumulation; Aspinwall \& Taylor, 1997) and (b) both objective and subjective controllability of one's present and future situation (cf. addressing self-regulation; Thoolen et al., 2007). For example, recognizing and acquiring resources might be tackled by encouraging newcomers to build a repertoire of temporal, financial, and social resources (Aspinwall \& Taylor, 1997). Improving controllability might be improved by (1) modifying a challenge appraisal, for example, by asking newcomers to envision former mastery experiences; (2) planning activities that might include both the specification of short-term occupational goals; and (3) long-range planning, including both action planning and coping planning (see also Sohl \& Moyer, 2009). Whereas action planning refers to the initiation of an action under favorable circumstances, coping planning is especially needed when potential barriers are likely to appear (Webb \& Sheeran, 2007). In sum, we assume that proactive coping can be enhanced by an intervention that is focused on resource accumulation and controllability (RAAC). We hypothesize that individuals who participate in such a carefully developed RAAC intervention become better at proactively coping, more so than persons without the intervention (cf. Hypothesis 1).

Hypothesis 1: A RAAC intervention increases proactive coping.

\section{Reemployment and Proactive Coping}

Saks, Uggerslev, and Fassina (2007) reported divergent effects of organizational socialization tactics depending on pre-entry experiences. Some socialization tactics especially showed stronger effects among recent graduates. Thus, previous job market experiences have an impact on the transition process to a new workplace (e.g., Bauer et al., 2007). For example, as unemployment has detrimental effects on mental health, the adaptation process could be particularly difficult for newcomers who were previously unemployed. In fact, research (e.g., McKee-Ryan, Song, Wanberg, \& Kinicki, 2005; Paul \& Moser, 2009) has shown that unemployment causes undesirable psychological consequences such as impaired mental health, low self-esteem, and a shift toward an external locus of control. Thus, the experience of unemployment might lead to a decrease in perceived competence as well as to a real loss of skills.

All these consequences of unemployment might represent obstacles for job adaptation after reemployment. From a proactive coping perspective, unemployed individuals often lack both resources 
(e.g., social support) and a perception of control over their situation. Even more important, unemployed job searchers often tend to cope more reactively (Rutter \& Jones, 2007). Hence, previously unemployed newcomers would need more time to increase proactive coping than would newcomers without recent unemployment experiences (i.e., job changers). Therefore, we expect that a RAAC intervention aiming at the increase of proactive coping should have a weaker effect in cases of organizational newcomers who were previously unemployed (cf. Hypothesis 2).

Hypothesis 2: Previous unemployment is associated with a weaker effect of a RAAC intervention on proactive coping.

\section{Proactive Coping and Adaptation Outcomes}

Previous research on proactivity has suggested positive effects on a range of adaptation outcomes (Greenglass \& Fiksenbaum, 2009; Thomas, Whitman, \& Viswesvaran, 2010), including job performance and job satisfaction (Seibert, Kraimer, \& Crant, 2001; Wanberg \& Kammeyer-Mueller, 2000). Saks and Ashforth (1997) proposed a framework for the effectiveness of socialization tactics and newcomer adjustment and differentiated between proximal and distal indicators of newcomer adjustment. Among the proximal outcomes, they outlined the importance of role clarity, perceived person-job fit, and person-organization fit. Distal outcomes relate to measures such as job satisfaction or intention to quit (cf. Saks, Uggerslev, \& Fassina, 2007).

Based on the assumption that organizational entry is a period of coping with both anticipated and occurring stressors, proactive coping should lead to better adaptation (Cooper-Thomas \& Anderson, 2006). Among those stressors, role ambiguity and role conflict might be the most crucial factors that should be addressed by socialization tactics (e.g., Bauer et al., 2007). Accordingly, Ellis et al. (2015) outlined in their review the importance of role clarity as an important indicator of effective socialization, especially from the perspective of the newcomer (Saks et al., 2007). Besides role clarity being a proximal outcome of organizational socialization, we also include a distal measure of organizational socialization that is important from the perspective of the organization, namely intention to quit (Bauer et al., 2007; Saks et al., 2007).

Role clarity. Entering a new organization is often accompanied by some degree of disorientation and even reality shock due to, for example, unfamiliar organizational culture, unclear performance expectations, or unusual colleagues' demeanors (Wang, Zhan, Maccune, \& Truxillo, 2011). Organizational newcomers face unfamiliar or unclear role expectations and thus have a need to make sense of the new environment and to clarify their role (Allen, 2006; Bauer \& Erdogan, 2011). Therefore, one important measure of newcomers' adjustment to a new workplace is role clarity (i.e., understanding job tasks and priorities; Bauer et al., 2007).

Early orientation programs have been considered as being crucial for the adjustment of newcomers (Saks et al., 2007) and are often seen as the main procedure to enhance role clarity by means of passing information about rules, priorities, and so on. Wanberg and Kammeyer-Mueller (2000) underlined the importance of relationship building, one of the proactivity aspects, as being associated with higher role clarity. Tang, Liu, Oh, and Weitz (2014) reported that engaging in proactive socialization tactics such as inquiry and observation were positively associated with newcomer role clarity. Also, the metaanalysis of Bauer, Bodner, Erdogan, Truxillo, and Tucker (2007) outlined that information seeking was significantly related to role clarity. Similarly, proactive coping should help newcomers in adapting to a new workplace, for example, by means of a self-directed exploration of job expectations and resources, which, in turn, should clarify one's role in the new organization (cf. Hypothesis 3).

Hypothesis 3: Proactive coping has a positive effect on role clarity. 
Intention to quit. From the organizations' perspective, intention to quit is a particularly important outcome of organizational socialization. Although some studies have investigated intention to quit in relation to proactivity (e.g., Wanberg \& Kammeyer-Mueller, 2000), evidence for an association specifically between proactive coping and intention to quit is lacking. Referring to research on proactive behaviors and socialization outcomes (Saks et al., 2011), we assume that people who, for example, are actively seeking information are likely to be more satisfied with their jobs and have a lower intention to quit. More specifically, proactive coping might contribute to the prevention or reduction of strain (Ângelo \& Chambel, 2012; Searle \& Lee, 2015), which, in turn, is related to turnover intention (Podsakoff, LePine, \& LePine, 2007). In sum, individuals high in proactive coping may be less likely to consider leaving a workplace (cf. Hypothesis 4).

Hypothesis 4: Proactive coping has a negative effect on intent to quit.

\section{Proactive Coping: Successful Onboarding or Rocking the Boat?}

Up to this point, we have drawn a rather "nice" picture of the role of proactivity, in general, and proactive coping, in particular. Remember that a colloquial term for the organizational socialization of newcomers is "onboarding" (e.g., Bauer \& Erdogan, 2011). Taking a new crew member on board can, of course, be easier if the entrant not only follows the rules but is also vigilant, eager to learn, and "knows the ropes." However, consider the case where the entrant has plenty of resources (e.g., knowledge) and has a strong interest in gaining some control by, for instance, starting to discuss how to navigate the boat. As both simply are not possible due to the existing organizational hierarchy and because the entrant might quickly reconsider the situation and want to leave the boat, this might create problems by the entrant who "rocks the boat."

In a similar vein, proactive coping cannot only mean that newcomers become prepared to either prevent or cope with stressors in a way that is in line with organizational goals (e.g., by learning activities, feedback seeking), but it can also mean that individuals reconsider their situation during organizational entry. If, for example, individuals perceive their personal resources as valuable but autonomy at the workplace as being too low, proactive coping could also mean changing the situation by leaving the organization. Therefore, the effects of proactive coping on intention to quit might be less clear than we have assumed in the previous section.

In their meta-analysis, Bauer and colleagues (2007) underlined pre-entry status as an important factor in improving the intention to remain; self-efficacy was more strongly related to intentions to remain for participants who changed from school to work compared to job changers. For job changers, enhancing role clarity might even entail adverse consequences because of a more critical assessment of the new job and thus lead to an increased temptation to quit the job, maybe due to the perception of a moderate person-job fit (Saks et al., 2007) or perceptions of underemployment (Maynard, Joseph, \& Maynard, 2006). Also, the more recent and positive experience of job prospects might enhance the intention to quit. Contrary, previously unemployed newcomers might be more reluctant to think about leaving their new workplace due to their limited resources, for example, job market prospects. Some studies (Bańka \& Wołowska, 2006; Grdinovac \&Yancey, 2012) pointed to a higher threat of job loss, unemployment rate, and unstable environments as leading employees to lower their intention to leave, which is especially true for those previously unemployed. Accordingly, we expect previously unemployed newcomers to less likely to quit a new job due to their past (negative) experiences associated with unemployment (Paul \& Moser, 2009), which might influence the perception and appreciation of their current job. For example, McKee-Ryan, Song, Wanberg, and Kinicki (2005) reported improvements in mental health and life satisfaction due to reemployment. Overall, these considerations suggest that pre-entry experience of organizational newcomers 
(previous unemployment vs. job change) will moderate the effect of proactive coping on intention to quit (cf. Hypothesis 5).

Hypothesis 5: The effect of proactive coping on intention to quit is moderated by previous unemployment.

\section{Method}

\section{Sample}

The participants of this study were employees of several electronic retail stores of the same company in Poland. The participants were recruited among new employees who were hired by the company and worked as retail salespersons in newly opened stores. These persons had not worked for this company in before and were therefore organizational newcomers. Overall, 172 organizational newcomers participated in the study. Fifty-three percent of the participants were female and the mean age was $M=$ 31.47 years (standard deviation $[S D]=9.79$ ). Concerning their pre-entry status, $44 \%$ of participants were previously unemployed. The mean period of unemployment of the previously unemployed participants was $M=7.77$ months $(S D=6.16)$.

\section{RAAC Intervention Program}

We developed an intervention for organizational newcomers that could be used either at work or at home. The intervention consists of a training booklet that includes various exercises aimed at a positive framing of job adaptation, goal setting and self-management, recognizing and accumulating resources, analyzing opportunities and threats, and proactive coping planning (the contents and methods of the booklet are described in Appendix Table A1). As the intervention targeted organizational newcomers, the examples in the booklet were related to the workplace.

In the booklet, participants were asked to envision a mastery experience in prior adaptation processes and were encouraged to create a positive and constructive outlook on adaptation to the new workplace. Subsequently, the participants collected and selected adaptation goals and developed strategies for transferring previous experiences into the current job. Another part of the booklet was devoted to the recognition and acquisition of one's personal and social resources. For instance, participants were asked to identify their personal resources and to reestablish or firm up the bonds with their social support network. Hereafter, the participants were requested to specify short-term occupational goals and to create a detailed plan of their adaptation process and accumulation of required resources. Concerning long-range planning, two different approaches were applied: action planning and coping planning. Action plans were based on precise descriptions of situations in which an individual was going to perform a specified action in order to attain the desirable goal, namely, positive work adaptation outcomes. During action planning, the participants specified goals and intentions that help to initiate and to pursue planned behaviors in certain situations. Coping planning refers to both the anticipation of potential threats and barriers of goal achievement, and self-regulation strategies for coping with these situations.

\section{Evaluation Design}

The study design consists of a treatment and a control group within a longitudinal design with three waves. The participants were recruited among the newly hired employees and were randomly assigned to the treatment or the control group. Every second newly hired employee was assigned to the treatment group and received the training booklet with exercises and questionnaires either directly after 
signing the job contract or within the first 2 weeks of employment. The other newly hired employees were assigned to the control group and received only the questionnaires.

The booklets were recollected after 2 weeks, which allowed us to control whether the booklet was used in the intended way. Please note that only participants, who returned the completed intervention booklet, were analyzed as belonging to the intervention group, while 18 participants who received an intervention booklet but completed only the questionnaires without having worked on the exercises were excluded from data analysis. A $t$ test showed no significant differences in the level of proactive coping between these groups at baseline, $t(170)=1.92, p=.057$. However, proactive coping is slightly lower in the treatment group, $M=2.81, S D=0.45$, than in the control group, $M=2.94$, $S D=0.44$. Therefore, we statistically controlled for group as described later.

Questionnaires were administered within a longitudinal design with three waves. The first data collection was at the time of the organizational entry and before the RAAC intervention (pretest, $N=172$ ). The second data collection was conducted 3 months later (posttest, $N=119$ ), and finally, data were collected 6 months after the intervention (follow-up, $N=99$ ). The 3 -month interval between measurements was chosen for reasons that were theoretical (e.g., this time frame allowed for observing the longer term consequences of the coping behaviors reported at the pretest and posttest; cf. Wanberg, 1997); moreover, the training might have greater benefits at later measurement periods because of its future orientation (Strauss \& Parker, 2015) and practical (i.e., to maintain the engagement of respondents and to reach all participants at the same workplace, since data were collected anonymously).

The same questionnaire was administered to all participants in the treatment and control group. Completion of questionnaires for the pretest and posttest surveys was done on a voluntary basis, no monetary compensation or other incentives were provided. Participants were invited to record some anonymous ID (e.g., nick name), so that individual responses could be matched over time by the research team.

\section{Measures}

Proactive coping. Proactive coping was assessed with the 14-item "Proactive Coping Scale" of the Proactive Coping Inventory (Polish version; Pasikowski, Sęk, Greenglass, \& Taubert, 2002). A sample item is "When I experience a problem, I take the initiative in resolving it." The participants answered each item on a 4-point rating scale ranging from 1 (never) to 4 (always). Higher scores indicate a higher level of proactive coping. The reliability in the current study was satisfying, Cronbach's $\alpha=.88$.

Role clarity. Role clarity was assessed using 10 items based on previous questionnaires (e.g., Chao, O'Leary-Kelly, Wolf, Klein, \& Gardner, 1994). Sample items are "I know the responsibilities and tasks of my job I was hired for" or "I know and understand this organization's objectives and goals." The items were answered on a 5-point scale ranging from 1 (strongly disagree) to 5 (strongly agree). The scale was scored in such a way that high scores indicated high role clarity. The reliability in the current study was satisfying, Cronbach's $\alpha=.89$. $^{1}$

Intention to quit. Intention to quit was assessed using 2 items. These items were adapted from Cammann, Fichman, Jenkins, and Klesh (1983): "I think about changing the job" and "I am looking for a new job." Responses ranged from 1 (never) to 4 (very often). The reliability was acceptable, Cronbach's $\alpha=.83 .^{2}$

Control variables. As control variables, we assessed age, gender, and previous unemployment at Time 1 (participants were asked whether they were unemployed, students, or employed before getting the current job). Since the sample does not contain any former students, we dummy coded previous unemployment with 0 (previously employed) and 1 (previously unemployed). We also included general 
self-efficacy as a control variable because of its similarity to coping (Gruman, Saks, \& Zweig, 2006; Schwarzer \& Taubert, 2002) as well as to proactive coping (Stanojević, Krstić, Jaredić, \& Dimitrijević, 2013). Self-efficacy was assessed by a Polish version of the 10-item General Self-Efficacy (GSE) Scale (Schwarzer, Jerusalem, \& Juczynski, 2008). A sample item is "I can always manage to solve dificult problems if I try hard enough." Responses are made on a 4-point scale ranging from 1 (not at all true) to 4 (exactly true); higher scores indicate higher general self-efficacy. The reliability in the current study was quite high, Cronbach's $\alpha=.92$.

\section{Analyses}

The participants received questionnaires at 3 times. Accordingly, we computed multilevel models for longitudinal data, with the respective waves on Level 1 and the subjects on Level 2 (Singer \& Willett, 2003). To control for changes over time, we considered the linear and quadratic effect of time. The RAAC intervention was dummy coded with 0 (no intervention) and 1 (intervention). Therefore, at Wave 1, both the treatment and the control group were coded with 0 because both groups have not received an intervention. As of Waves 2 and 3, the treatment group had already received the intervention, and therefore, we coded this group with 1 , whereas the control group was coded with 0 . Thus, this variable reflects the effect of having received an intervention and therefore controls for both groups.

Hypotheses 3 and 4 consider proactive coping as predictor. Since the questionnaires were answered 3 times, proactive coping was repeatedly assessed and thus can vary between the waves (Level 1) and between persons (Level 2). Therefore, we centered proactive coping (Time 1 centering; Singer \& Willett, 2003).

\section{Results}

Table 1 presents the descriptive statistics and correlations between the study variables. In the following, we test whether the RAAC intervention enhances proactive coping. Furthermore, we address the effect of the RAAC intervention and proactive coping on two adaptation outcomes, namely, role clarity and intention to quit.

\section{Enhancing Proactive Coping With an Intervention}

Table 2 shows the results of a linear mixed model predicting the increase in proactive coping. In Model 1a, we controlled for gender, age, previous unemployment, and general self-efficacy. Among those variables, age is related to proactive coping, $b=-.01, p<.001$. Previous unemployment, that is, whether the participants were unemployed before entering the organization, has no effect on proactive coping, $b=-.06, p=.279$, whereas general self-efficacy exerts a positive effect, $b=.37, p<.001$. Furthermore, we controlled for the linear and quadratic effects of time, which were revealed as being significant. The positive linear effect of time indicates that proactive coping increases over time, $b=$ $.17, p=.002$, though the negative quadratic effect describes decreasing slopes, $b=-.07, p=.012$.

Hypothesis 1 assumes an effect of the intervention on proactive coping. Model $1 \mathrm{~b}$ outlines a positive effect of the RAAC intervention, $b=.17, p<.001$. Thus, participants who worked with the intervention booklet report higher levels of proactive coping, confirming Hypothesis 1. Hypothesis 2 assumes that previous unemployment is associated with a weaker effect of the intervention on proactive coping. Consistent with our expectations, Model 1c outlines an interaction effect of previous unemployment and the RAAC intervention, $b=-.20, p=.010$. Thus, the intervention has less impact in case of previous unemployment, confirming Hypothesis 2. 


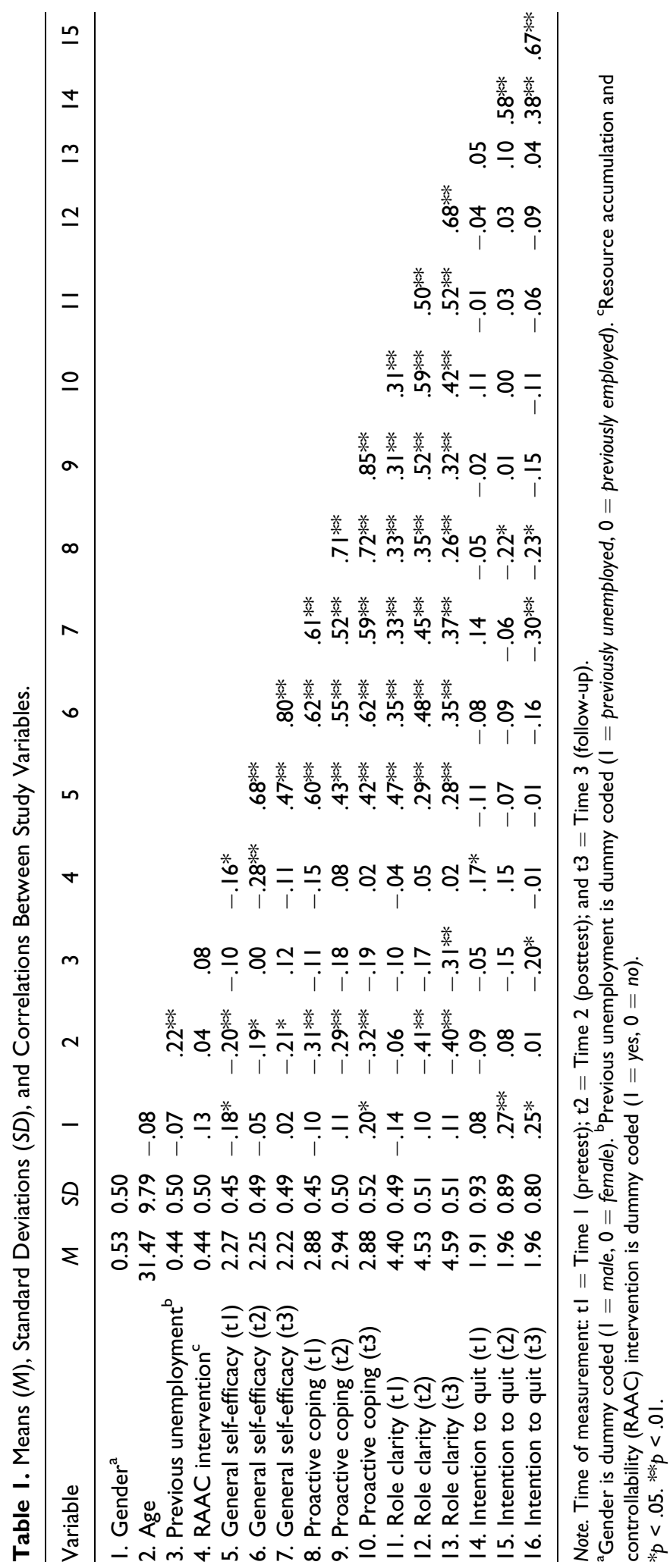




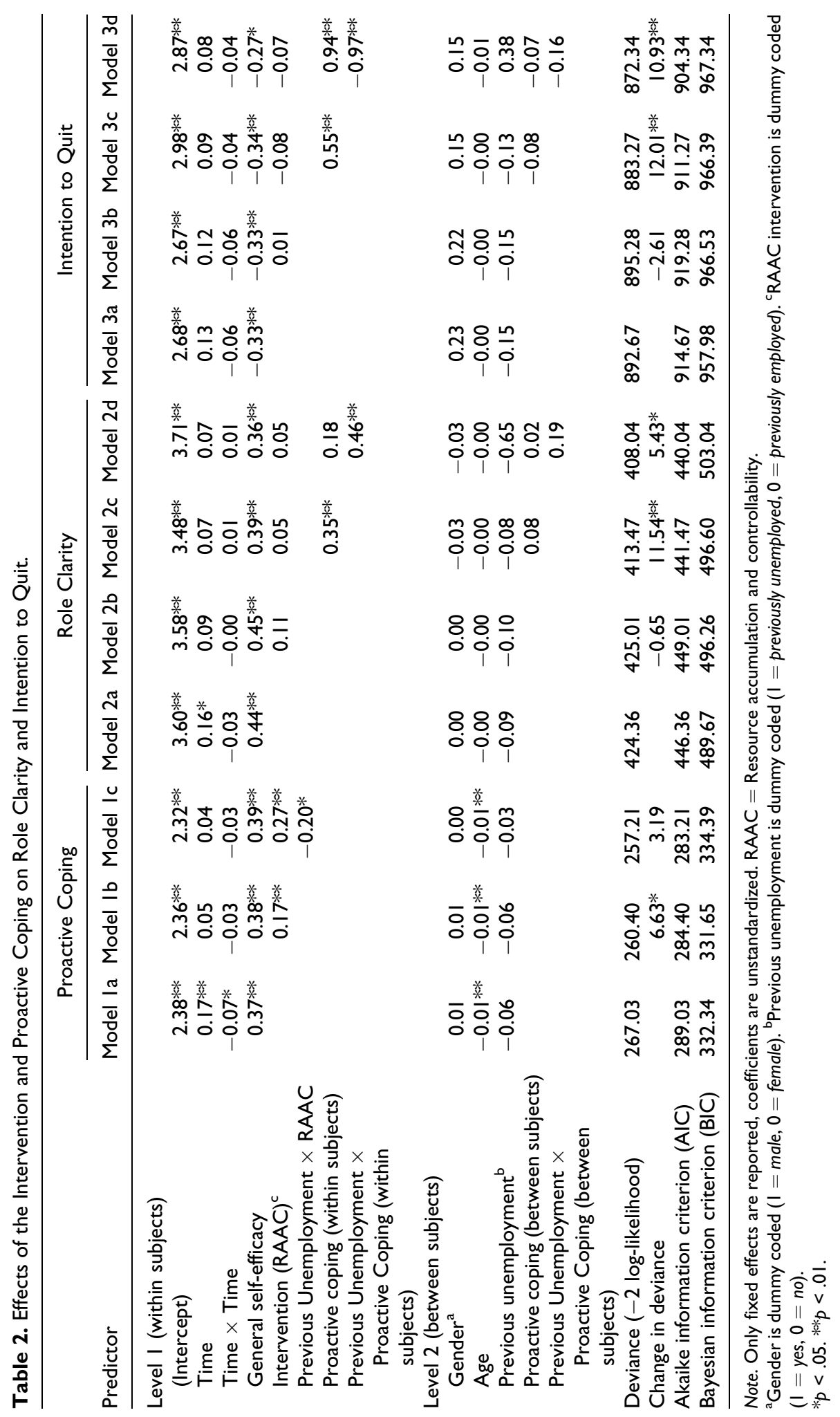




\section{Adaptation Outcomes}

Role clarity. Table 2 contains several models predicting role clarity. Again, we first included gender, age, previous unemployment, general self-efficacy, and the linear and quadratic effect of time as control variables, yielding no effects on role clarity, except for general self-efficacy, $b=.44, p<.001$, and the linear effect of time, $b=.16, p=.020$ (Model 2a). In Model 2b, we included the RAAC intervention as additional predictor, yielding no effect, $b=.11, p=.077$. Thus, contrary to expectations, the intervention has no direct effect on role clarity.

Hypothesis 3 assumes that proactive coping results in increased role clarity. Accordingly, Model 2c includes proactive coping as a covariate at Level 1 (within subjects) as well as at Level 2 (between subjects). Proactive coping on Level 2 reflects initial differences between the individuals, whereas proactive coping at Level 1 describes the increase in proactive coping at the posttest and follow-up compared to the pretest (within subjects). According to Model 2c, proactive coping (Level 1, within subjects) has a positive effect on role clarity, $b=.35, p<.001$, whereas proactive coping (Level 2, between subjects) has no effect, $b=.08, p=.309$. These results substantiate the importance of the RAAC intervention because it is the increase in proactive coping that contributes to role clarity rather than the existing level of proactive coping before the intervention. This result confirms Hypothesis 3.

Since both effects (Hypotheses 1 and 3) were significant, we additionally tested the indirect effect of the intervention on role clarity through proactive coping (Imai, Keele, \& Tingley, 2010). To test for indirect effects within the framework of multilevel analysis, we followed the instructions of Zhang, Zyphur, and Preacher (2009) and controlled for group-mean centered proactive coping at Level 2 (2-1-1 model; Zhang, Zyphur, \& Preacher, 2009). Based on the fully specified models, including all covariates (i.e., Model $1 \mathrm{~b}$ and Model 2d), we found an indirect effect, $\bar{\delta}(t)=0.07, p<.001$, confidence interval (CI) $95 \%$ [0.023, $0.115]$. Overall, the intervention results in higher role clarity by means of increased proactive coping.

Intention to quit. Table 2 also contains several models predicting intention to quit. In Model 3a, we again included gender, age, previous unemployment, and the linear and quadratic effect of time as control variables, yielding no significant effects. However, general self-efficacy lowers the intention to quit, $b=-.33, p=.001$. In Model $3 \mathrm{~b}$, we included the intervention as an additional predictor, which has no effect on intention to quit, $b=.01, p=.911$.

Hypothesis 4 assumes that proactive coping results in a lower level of intention to quit. Accordingly, Model 3c includes proactive coping as covariate at Level 1 (within subjects) as well as at Level 2 (between subjects). Contrary to our expectations, proactive coping (Level 1, within subjects) has a positive effect on intention to quit, $b=.55, p<.001$. Thus, Hypothesis 4 is not confirmed. Moreover, proactive coping (Level 2, between subjects) has no influence, $b=-.08, p=.640$. A supplementary analysis indicates an indirect effect of the RAAC intervention on the intention to quit through proactive coping, $\bar{\delta}(t)=0.09, p<.001$, CI 95\% [0.027, 0.174].

Finally, Hypothesis 5 predicts that the effect of proactive coping (within subjects) on intention to quit is moderated by previous unemployment. In fact, Model $3 \mathrm{~d}$ outlines a negative interaction effect of proactive coping (within subjects) and previous unemployment, $b=-.97, p<.001$, confirming Hypothesis 5. With regard to the positive main effect of proactive coping (within subjects) on intention to quit, $b=.94, p<.001$, the increase in proactive coping is leading to a strong intention to quit for those participants who were previously employed (i.e., job changers), whereas for the previously unemployed participants, there is no effect of proactive coping on intention to quit.

\section{Discussion}

The current study contributed in several ways to our understanding of the importance of proactive coping in the context of adaptation to a new workplace. The proposed RAAC intervention enhances 
proactive coping of organizational newcomers. Since any intervention should be discussed with respect to the sustainability (vs. relapse) of the effects, we collected data 3 months (posttest) and 6 months after the intervention (follow-up). In particular, the analyses consider the mean effect of the intervention for the posttest as well as the follow-up, and thus take into account the short-term as well as the long-term effect of the intervention. In addition, the study design comprises a treatment and control group and therefore allows us to control for maturation and testing effects. Thus, the intervention is not bound to a temporary effect but created an enduring increase in proactive coping, even over and above general self-efficacy beliefs.

Furthermore, moderation analysis revealed previous unemployment as an important factor in proactive coping of organizational newcomers. In particular, the effect of the RAAC intervention had less impact on proactive coping for participants who were previously unemployed. Since the situation of unemployment is often unpredictable, the unemployed participants might in fact have become reactive copers. Rather than enhancing coping, most programs for the unemployed are focused on intensifying job-search skills and behaviors or decreasing negative symptoms related to unemployment (e.g., Eden \& Aviram, 1993). Therefore, previously unemployed workers might need more time and guidance to change this orientation into proactivity. One might even speculate that the logic of proactive coping is only partially appropriate for the previously unemployed because unemployment itself can be characterized as a situation of chronic stress, rendering proactive coping rather unlikely (Aspinwall \& Taylor, 1997).

Further analyses revealed that proactive coping was a predictor of one important adaptation outcome: role clarity. Since role clarity refers to a level of understanding one's own job, related expectancies, and responsibilities, it can be developed for a newcomer through reading information, talking to coworkers about the job or seeking information and feedback (Aspinwall \& Taylor, 1997). Proactive copers accumulate more personal and job-specific resources and are able to invest them efficiently to improve their understanding of their work role. Moreover, Gruman, Saks, and Zweig (2006) assumed that proactive behaviors mediate the relationship between socialization tactics and outcomes. More specifically, the meta-analysis of Saks et al. (2007) provides evidence that uncertainty reduction (i.e., low role conflict and role ambiguity) and perceptions of person-job fit and person-organization fit partially mediate the relationship between socialization tactics and distal measures of newcomer adjustment. Accordingly, our analyses confirmed an indirect effect of the RAAC intervention onto role clarity by means of proactive coping. More important, because an increase in proactive coping (within subjects) fosters role clarity - rather than the initial level of proactive coping (between subjects) — our results underline the effectiveness of the intervention. Specifically, it demonstrates that newcomers' tendency to cope in a proactive way leads to better outcomes in clarifying their own role in the new workplace, which is especially true for those participants who gained most from the RAAC intervention. This also follows the call to focus not only on long-term socialization outcomes but likewise on proximal outcomes like role clarity (Bauer et al., 2007).

The current research draws the focus on organizational socialization from the newcomers' perspective and thus follows the proposition of Ellis et al. (2015) that resources can contribute to the socialization process. However, this study has shown that proactive coping might also lead to undesirable outcomes from the perspective of the employing organization. Previous results on the influence of proactive coping on intention to quit (Wanberg \& Kammeyer-Mueller, 2000) pointed to the pivotal role of proactive behaviors in decreasing intention to quit, whereas our findings indicate that proactive coping can even contribute to a stronger intention to quit. Since proactive employees continuously search for learning opportunities and challenging tasks, prompting proactivity might lead to increased mobility and willingness to change the organization, if they do not find the possibility of personal growth within the current workplace (e.g., Maynard et al., 2006). Also, enhancing proactivity might reduce the transaction costs of leaving an organization and joining a new one for a certain job. In fact, such employees might be "hypervigilant," which has been assumed to be a limiting condition for the 
helpful effects of proactive coping (Aspinwall \& Taylor, 1997). This finding agrees with recent studies also reporting a complex effect of proactivity (e.g., Seibert et al., 2001). In this sense, our results outline that the relationship between proactive coping and intention to quit is weaker for those who were previously unemployed. Regarding the adverse effects of unemployment (Paul \& Moser, 2009), the experience of unemployment might result in decreasing levels of motivation to leave the workplace, irrespectively of the level of proactive coping, at least in the short run.

Our supplementary analysis indicated an indirect effect of the RAAC intervention on intention to quit by means of proactive coping. This finding contributes to previous research that proposed proactive behavior as mediator of the relationship between support of organizational newcomers from coworkers and supervisors and more distal work outcomes, including withdrawal behaviors (Kammeyer-Mueller, Wanberg, Rubenstein, \& Song, 2012).

\section{Limitations}

This study showed that proactive coping can be improved in newcomers and that the increase in proactive coping contributes to specific adaptation outcomes like role clarity. Nevertheless, our study has some limitations. First, the study was based on a relatively small sample of participants. Note that we were, at least initially, able to reach all organizational newcomers of the respective company who were hired in newly opened stores in the entire country. Second, the present study was focused on jobs in retail stores that are low both in complexity and autonomy, and thus the potential of proactive coping was rather limited. This might also explain the high level of role clarity which was identified even before the training intervention. To enhance statistical power, future research should investigate jobs that are characterized by a higher job complexity and offer sufficient opportunities for proactive coping. Third, the study suffers from dropout as the response rate dropped to $58 \%$ in Wave 3 . However, the number of dropouts does not differ between treatment and control group, $\chi^{2}(d f=2, N=390)=1.36, p$ $=.508$. Thus, we can exclude a selective dropout, even though, there was no possibility to control for the reasons of the drop out (e.g., refusal to participate vs. termination of contracts). Finally, another limitation might be the lack of a comprehensive implementation control. Within the present study, booklets were recollected and screened in order to ensure that the participants in the treatment group actually worked on the booklets. Future studies could deepen the knowledge on crucial aspects of implementation by recording how often and how long the participants worked on the booklets. Web-based approaches provide promising characteristics, since the use of the booklet can be recorded and coaching requests can be send by e-mail. In addition, web-based booklets are permanently available for the participants. Within the present study, the booklets were recollected after 2 weeks, which might have weakened the effects of the intervention in the long run.

\section{Implications and Directions for Future Research}

The current evaluation study has both practical implications and suggests directions for future research. The effect of the intervention on proactive coping supports our assumption of proactive coping as being malleable. Furthermore, the effect of the RAAC intervention depended on employees' pre-entry experience. In particular, reemployed individuals benefited less from the intervention with regard to proactive coping than job changers. These findings are of practical importance for the specification of the target groups of this intervention. With regard to organizational newcomers, a proactive coping intervention is especially effective for those participants who changed their workplace. However, there is still a need to identify methods that would be as effective for previously unemployed individuals. They should not be excluded from the intervention for the reason of their previous unemployment, what could make them feel humiliated, limited, or ignored. Hence, future interventions should take into account these specific circumstances and provide means to improve proactive coping 
of reemployed newcomers. Detailed knowledge about specific problems and consequences of newcomer integration should provide fruitful starting points for the development of specific interventions and recommendations for various groups of employees.

The study found ambivalent effects of proactive coping, including an increase in intention to quit, though, from the individuals' perspective, proactivity promotes ongoing career development, which also includes the search for career opportunities even outside the respective organization. From the organization's perspective, fostering proactive coping should be accompanied by means to increase organizational commitment. Overall, there is still a need to investigate organizational benefits and costs of newcomers' proactive coping in more detail as well as managers' perception of newcomer proactive behaviors (Ellis, Nifadkar, Bauer, \& Erdogan, 2017).

Future research should investigate the processes by which proactive behaviors exert their influence on outcomes. Ashforth, Sluss, and Saks (2007) found that the socialization processes influence newcomers' adjustment apart from its content. Specifically, both institutionalized socialization and proactive behavior were directly related to intentions to quit. According to Saks et al. (2007), there is a need for longitudinal measures of socialization tactics to control temporal differences over time.

\section{Conclusions}

Our results demonstrate that a RAAC intervention can enhance proactive coping, which in turn improves role clarity, and therefore contributes to the "onboarding" of organizational newcomers. However, proactive coping might also result in a stronger intention to quit. To put it in other words, increasing proactive coping in organizational newcomers can also make them "rock the boat."

\section{Appendix}

Table Al. Description of the Training Intervention.

\begin{tabular}{|c|c|c|}
\hline Topic & Content & Instructions \\
\hline $\begin{array}{l}\text { Positive framing of job } \\
\text { adaptation }\end{array}$ & $\begin{array}{l}\text { Reflection of past experiences with } \\
\text { adaptation processes and reframing as } \\
\text { opportunities }\end{array}$ & $\begin{array}{l}\text { - Making a list of previous adaptation } \\
\text { strategies } \\
\text { - Collection of adaptation barriers and } \\
\text { reformulation as opportunities } \\
\text { - Indication of short-term and long-term } \\
\text { benefits of adaptation strategies }\end{array}$ \\
\hline $\begin{array}{l}\text { Goal setting and } \\
\text { enhancement of } \\
\text { self-management } \\
\text { skills }\end{array}$ & $\begin{array}{l}\text { Structured processing of goal setting, } \\
\text { priority-setting, and action planning }\end{array}$ & $\begin{array}{l}\text { - Collection of adaptation goals (e.g., } \\
\text { acquisition of skills, promotion) } \\
\text { - Selection of the most important goals } \\
\text { - Formulation of action plans (e.g., } \\
\text { weekly plan on when and how to } \\
\text { undertake specific actions) }\end{array}$ \\
\hline $\begin{array}{l}\text { Recognition and } \\
\text { accumulation of } \\
\text { resources }\end{array}$ & $\begin{array}{l}\text { Identification and extension of personal } \\
\text { and social resources }\end{array}$ & $\begin{array}{l}\text { - Making a list of existing and required } \\
\text { resources (e.g., knowledge, skills, and } \\
\text { networks) } \\
\text { - Formulation of action plans for the } \\
\text { accumulation of required resources } \\
\text { (e.g., "What can I do to increase my } \\
\text { resources" or "Who can I ask for } \\
\text { help?") }\end{array}$ \\
\hline
\end{tabular}


Table AI. (continued)

\begin{tabular}{|c|c|c|}
\hline Topic & Content & Instructions \\
\hline $\begin{array}{l}\text { Analyzing } \\
\text { opportunities and } \\
\text { threats }\end{array}$ & $\begin{array}{l}\text { Recognition and reinterpretation of } \\
\text { opportunities and threats as well as } \\
\text { ensuring perceived control }\end{array}$ & $\begin{array}{l}\text { - Indication of both benefits and costs of } \\
\text { goal achievement, and opportunities } \\
\text { and threats of goal achievement } \\
\text { - Reframing of situations by focusing on } \\
\text { positive aspects and perceiving } \\
\text { situations as opportunities rather than } \\
\text { threats } \\
\text { - Encouragement of participants } \\
\text { regarding their influence on situations }\end{array}$ \\
\hline $\begin{array}{l}\text { Proactive coping } \\
\text { planning }\end{array}$ & $\begin{array}{l}\text { Anticipation of barriers and planning of } \\
\text { coping strategies }\end{array}$ & $\begin{array}{l}\text { - Imagination of three potential barriers } \\
\text { - Specification of resources to overcome } \\
\text { these barriers (e.g., "If I do not have } \\
\text { enough information about a product, } \\
\text { then I can ask Maria") }\end{array}$ \\
\hline
\end{tabular}

\section{Declaration of Conflicting Interests}

The author(s) declared no potential conflicts of interest with respect to the research, authorship, and/or publication of this article.

\section{Funding}

The author(s) disclosed receipt of the following financial support for the research, authorship, and/or publication of this article: This work has been supported by the Polish National Science Center (NCN) within the project "Proactive Coping and Adaptation to a New Workplace After Reemployment" (Project No. 2013/10/M/HS6/00550). The first author was also funded by the German Academic Exchange Service (DAAD).

\section{Notes}

1. The measure of role clarity has also been used in an independent study with 121 employees of another electronic retail company in Poland (Ślebarska, 2017). Participants' mean age was 33.02 years (standard deviation $=6.34$ ) and $31 \%$ of the participants were female. The reliability of the measure of role clarity was Cronbach's $\alpha=.87$. This employee survey included additional measures, particularly for job satisfaction and perceived stress that served as validation criteria. Participants assessed their job satisfaction regarding different facets (e.g., pay, coworkers, and supervisor; cf. Kinicki, McKee-Ryan, Schriesheim, \& Carson, 2002). We aggregated these facets to a compound index of job satisfaction; the reliability of this measure was Cronbach's $\alpha=.86$. Stress was assessed with the Perceived Stress Scale (PSS-10; Juczyński \& Ogińska-Bulik, 2009); the reliability of the PSS-10 was Cronbach's $\alpha=.84$. In the employee survey, role clarity was positively related to job satisfaction, $r=.32, p<.001$, and negatively related to perceived stress, $r=-.42, p<.001$ (Ślebarska, 2017). Overall, these results substantiate the reliability and validity of the measure of role clarity.

2. The measure of intention to quit has been used in another study (Ślebarska, 2017; cf. Note 1). The reliability of the measure of intention to quit was Cronbach's $\alpha=.79$. Intention to quit was negatively correlated to job satisfaction, $r=-.49, p<.001$, and the positive correlation with perceived stress was statistically significant at a marginal level, $r=.17, p=.057$ (Ślebarska, 2017). Overall, these results confirm the reliability and validity of our measure of intention to quit.

\section{References}

Allen, D. G. (2006). Do organizational socialization tactics influence newcomer embeddedness and turnover? Journal of Management, 32, 237-256. doi:10.1177/0149206305280103 
Ângelo, R. P., \& Chambel, M. J. (2012). The role of proactive coping in the Job Demands-Resources Model: A cross-section study with firefighters. European Journal of Work and Organizational Psychology, 23, 203-216. doi:10.1080/1359432x.2012.728701

Ashforth, B. E., Sluss, D. M., \& Saks, A. M. (2007). Socialization tactics, proactive behavior, and newcomer learning: Integrating socialization models. Journal of Vocational Behavior, 70, 447-462. doi:10.1016/j.jvb. 2007.02.001

Aspinwall, L., \& Taylor, S. (1997). A stitch in time: Self-regulation and proactive coping. Psychological Bulletin, 121, 417-436. doi:10.1037/0033-2909.121.3.417

Bańka, A., \& Wołowska, A. (2006). Zmiana rzeczywistości organizacyjnej a postawy wobec pracy: Analiza typów przywiązania i zaangażowania w prace [Changing organizational realities and attitudes towards work: Analysis of attachment types and work engagement]. In A. Biela, B. Rożnowski, \& A. Bańka (Eds.), Praca $i$ organizacja $w$ procesie zmian [Work and organization in the process of change] (pp. 123-139). Poznań, Poland: Stowarzyszenie Psychologia i Architektura.

Bauer, T., Bodner, T., Erdogan, B., Truxillo, D., \& Tucker, J. (2007). Newcomer adjustment during organizational socialization: A meta-analytic review of antecedents, outcomes, and methods. Journal of Applied Psychology, 92, 707-721. doi:10.1037/0021-9010.92.3.707

Bauer, T. N., \& Erdogan, B. (2011). Organizational socialization: The effective onboarding of new employees. In S. Zedeck (Ed.), APA handbook of industrial and organizational psychology (Vol. 3, pp. 51-64). Washington, DC: APA Press.

Bode, C., de Ridder, D. T. D., Kuijer, R. G., \& Bensing, J. M. (2007). Effects of an intervention promoting proactive coping competencies in middle and late adulthood. The Gerontologist, 47, 42-51. doi:10.1093/geront/47. 1.42

Cammann, C., Fichman, M., Jenkins, D., \& Klesh, J. (1983). Assessing the attitudes and perceptions of organizational members. In S. E. Seashore, E. E. Lawler III, P. H. Mirvis, \& C. Cammann (Eds.), Assessing organizational change: A guide to methods, measures, and practices (pp. 71-138). New York, NY: Wiley.

Chao, G. T., O'Leary-Kelly, A. M., Wolf, S., Klein, H. J., \& Gardner, P. D. (1994). Organizational socialization: Its content and consequences. Journal of Applied Psychology, 79, 730-743. doi:10.1037/0021-9010.79. 5.730

Cooper-Thomas, H. D., \& Anderson, N. (2006). Organizational socialization: A new theoretical model and recommendations for future research and HRM practices in organizations. Journal of Managerial Psychology, 21, 492-516. doi:10.1108/02683940610673997

Demerouti, E., Bakker, A. B., Nachreiner, F., \& Schaufeli, W. B. (2001). The job demands-resources model of burnout. Journal of Applied Psychology, 86, 499-512. doi:10.1037/0021-9010.86.3.499

Drummond, S., \& Brough, P. (2016). Proactive coping and preventive coping: Evidence for two distinct constructs? Personality and Individual Differences, 92, 123-127. doi:10.1016/j.paid.2015.12.029

Eden, D., \& Aviram, A. (1993). Self-efficacy training to speed reemployment: Helping people to help themselves. Journal of Applied Psychology, 78, 352-360. doi:10.1037/0021-9010.78.3.352

Ellis, A. M., Bauer, T. N., Mansfield, L. R., Erdogan, B., Truxillo, D. M., \& Simon, L. S. (2015). Navigating uncharted waters: Newcomer socialization through the lens of stress theory. Journal of Management, 41, 203-235. doi:10.1177/0149206314557525

Ellis, A. M., Nifadkar, S. S., Bauer, T. N., \& Erdogan, B. (2017). Newcomer adjustment: Examining the role of managers' perception of newcomer proactive behavior during organizational socialization. Journal of Applied Psychology, 102, 993-1001. doi:10.1037/ap10000201

Grdinovac, J. A., \& Yancey, G. B. (2012). How organizational adaptations to recession relate to organizational commitment. The Psychologist-Manager Journal, 15, 6-24. doi:10.1080/10887156.2012.649089

Greenglass, E. R. (2002). Proactive coping. In E. Frydenberg (Ed.), Beyond coping: Meeting goals, vision, and challenges (pp. 37-62). London, England: Oxford University Press.

Greenglass, E. R., \& Fiksenbaum, L. (2009). Proactive coping, positive affect, and well-being: Testing for mediation using path analysis. European Psychologist, 14, 29-39. doi:10.1027/1016-9040.14.1.29 
Gruman, J. A., \& Saks, A. M. (2011). Socialization preferences and intentions: Does one size fit all? Journal of Vocational Behavior, 79, 419-427. doi:10.1016/j.jvb.2011.04.006

Gruman, J. A., Saks, A. M., \& Zweig, D. I. (2006). Organizational socialization tactics and newcomer proactive behaviors: An integrative study. Journal of Vocational Behavior, 69, 90-104. doi:10.1016/j.jvb.2006.03.001

Imai, K., Keele, L., \& Tingley, D. (2010). A general approach to causal mediation analysis. Psychological Methods, 15, 309-334. doi:10.1037/a0020761

Juczyński, Z., \& Ogińska-Bulik, N. (2009). Narzędzia pomiaru stresu i radzenia sobie ze stresem [Tools measuring stress and coping with stress]. Warszawa, Poland: Pracownia Testów Psychologicznych Polskiego Towarzystwa Psychologicznego.

Kammeyer-Mueller, J., Wanberg, C., Rubenstein, A., \& Song, Z. (2012). Support, undermining, and newcomer socialization: Fitting in during the first 90 days. Academy of Management Journal, 56, 1104-1124. doi:10. 5465/amj.2010.0791

Kinicki, A. J., McKee-Ryan, F. M., Schriesheim, C. A., \& Carson, K. P. (2002). Assessing the construct validity of the Job Descriptive Index: A review and meta-analysis. Journal of Applied Psychology, 87, 14-32. doi:10. 1037//0021-9010.87.1.14

Krieger, H. (2010). Optimizing mobility: Europe needs more and better geographical labour mobility. In C. Kuptsch (Ed.), The internationalization of labour markets (pp. 135-164). Geneva, Switzerland: International Institute for Labour Studies.

Maynard, D. C., Joseph, T. A., \& Maynard, A. M. (2006). Underemployment, job attitudes, and turnover intentions. Journal of Organizational Behavior, 27, 509-536. doi:10.1002/job.389

McKee-Ryan, F., Song, Z., Wanberg, C. R., \& Kinicki, A. J. (2005). Psychological and physical well-being during unemployment: A meta-analytic study. Journal of Applied Psychology, 90, 53-76. doi:10.1037/0021-9010.90. 1.53

Pasikowski, T., Sęk, H., Greenglass, E. R., \& Taubert, S. (2002). The Proactive Coping Inventory—Polish adaptation. Polish Psychological Bulletin, 33, 41-46.

Paul, K. I., \& Moser, K. (2009). Unemployment impairs mental health: Meta-analyses. Journal of Vocational Behavior, 74, 264-282. doi:10.1016/j.jvb.2009.01.001

Podsakoff, N. P., LePine, J. A., \& LePine, M. A. (2007). Differential challenge stressor-hindrance stressor relationships with job attitudes, turnover intentions, turnover, and withdrawal behavior: A meta-analysis. Journal of Applied Psychology, 92, 438-454. doi:10.1037/0021-9010.92.2.438

Reicherts, M., \& Pihet, S. (2000). Job newcomers coping with stressful situations: A micro-analysis of adequate coping and well-being. Swiss Journal of Psychology, 59, 303-316. doi:10.1024//1421-0185.59.4. 303

Rutter, M. E., \& Jones, J. V. (2007). The job club redux: A step forward in addressing the career development needs of counselor education students. Career Development Quarterly, 55, 280-288. doi:10.1002/j.21610045.2007.tb00084.x

Saks, A. M., \& Ashforth, B. E. (1997). Organizational socialization: Making sense of the past and present as a prologue for the future. Journal of Vocational Behavior, 51, 234-279. doi:10.1006/jvbe.1997.1614

Saks, A. M., \& Gruman, J. A. (2012). Getting newcomers on board: A review of socialization practices and introduction to socialization resources theory. In C. R. Wanberg (Ed.), The Oxford handbook of organizational socialization (pp. 27-55). New York, NY: Oxford University Press.

Saks, A. M., Gruman, J. A., \& Cooper-Thomas, H. (2011). The neglected role of proactive behavior and outcomes in newcomer socialization. Journal of Vocational Behavior, 79, 36-46. doi:10.1016/j.jvb. 2010.12.007

Saks, A. M., Uggerslev, K. L., \& Fassina, N. E. (2007). Socialization tactics and newcomer adjustment: A metaanalytic review and test of a model. Journal of Vocational Behavior, 70, 413-446. doi:10.1016/j.jvb.2006.12. 004

Schwarzer, R., Jerusalem, M., \& Juczynski, Z. (2008). Polish version of the general self-efficacy scale. Retrieved from http://userpage.fu-berlin.de/ health/polish.htm 
Schwarzer, R., \& Taubert, S. (2002). Tenacious goal pursuits and striving toward personal growth: Proactive coping. In E. Frydenberg (Ed.), Beyond coping: Meeting goals, visions, and challenges (pp. 19-35). London, England: Oxford University Press.

Searle, B. J., \& Lee, L. (2015). Proactive coping as a personal resource in the expanded job demands-resources model. International Journal of Stress Management, 22, 46-69. doi:10.1037/a0038439

Seibert, S. E., Kraimer, M. L., \& Crant, J. M. (2001). What do proactive people do? A longitudinal model linking proactive personality and career success. Personnel Psychology, 54, 845-874. doi:10.1111/j.1744-6570.2001. tb00234.x

Singer, J. D., \& Willett, J. B. (2003). Applied longitudinal data analysis: Modeling change and event occurrence. New York, NY: Oxford University Press.

Ślebarska, K. (2017). Proactivity, job satisfaction, and psychological strain. Unpublished raw data.

Sohl, S. J., \& Moyer, A. (2009). Refining the conceptualization of a future-oriented self-regulatory behavior: Proactive coping. Personality and Individual Differences, 47, 139-144. doi:10.1016/j.paid.2009. 02.013

Stanojević, D., Krstić, M., Jaredić, B., \& Dimitrijević, B. (2013). Proactive coping as a mediator between resources and outcomes: A structural equations modeling analysis. Applied Research in Quality of Life, 9 , 871-885. doi:10.1007/s11482-013-9274-2

Stephens, K. K., \& Dailey, S. L. (2012). Preentry organizational exposure situated organizational identification in newcomers: Impacts of preentry organizational exposure. Management Communication Quarterly, 26, 404-422. doi:10.1177/0893318912440179

Strauss, K., \& Parker, S. K. (2015). Intervening to enhance proactivity in organizations: Improving the present or changing the future. Journal of Management, 20, 1-29. doi:10.1177/0149206315602531

Tang, C., Liu, Y., Oh, H., \& Weitz, B. (2014). Socialization tactics of new retail employees: A pathway to organizational commitment. Journal of Retailing, 90, 62-73. doi:10.1016/j.jretai.2013.11.002

Thomas, J. P., Whitman, D. S., \& Viswesvaran, C. (2010). Employee proactivity in organizations: A comparative meta-analysis of emergent proactive constructs. Journal of Occupational and Organizational Psychology, 83, 257-300. doi:10.1348/096317910X502359

Thoolen, B., de Ridder, D., Bensing, J., Gorter, K., \& Rutten, G. (2007). Beyond Good Intentions: The development and evaluation of a proactive self-management course for patients recently diagnosed with Type 2 diabetes. Health Education Research, 23, 53-61. doi:10.1093/her/cyl160

U.S. Bureau of Labor Statistics. (2015). Number of jobs held, labor market activity, and earnings growth among the youngest baby boomers: Results from a longitudinal survey. Retrieved from https://www.bls.gov/news. release/pdf/nlsoy.pdf

Van Hooft, E. A. J., \& Noordzij, G. (2009). The effects of goal orientation on job search and reemployment: A field experiment among unemployed job seekers. Journal of Applied Psychology, 94, 1581-1590. doi:10.1037/ a0017592

Wanberg, C. R. (1997). Antecedents and outcomes of coping behaviors among unemployed and reemployed individuals. Journal of Applied Psychology, 82, 731-744. doi:10.1037/0021-9010.82.5.731

Wanberg, C. R., \& Kammeyer-Mueller, J. D. (2000). Predictors and outcomes of proactivity in the socialization process. Journal of Applied Psychology, 85, 373-385. doi:10.1037/0021-9010.85.3.373

Wang, M., Zhan, Y., Maccune, E., \& Truxillo, D. (2011). Understanding newcomers' adaptability and workrelated outcomes: Testing the mediating roles of perceived P-E fit variables. Personnel Psychology, 64, 163-189. doi:10.1111/j.1744-6570.2010.01205.x

Webb, T. L., \& Sheeran, P. (2007). How do implementation intentions promote goal attainment? A test of component processes. Journal of Experimental Social Psychology, 43, 295-302. doi:10.1016/j.jesp.2006. 02.001

Zhang, Z., Zyphur, M. J., \& Preacher, K. J. (2009). Testing multilevel mediation using hierarchical linear models: Problems and solutions. Organizational Research Methods, 12, 695-719. doi:10.1177/1094428108327450 


\section{Author Biographies}

Katarzyna Ślebarska earned her doctoral degree from the University of Silesia in Katowice, Poland, and is currently a lecturer and research associate at the Institute of Psychology of the University of Silesia in Katowice. Her research interests include unemployment, job search behavior, reemployment, and organizational behavior (coping strategies and adaptation). She is a member of the European Association of Work and Organizational Psychology and National Career Counseling Forum. Her leisure activities include swimming and skiing.

Roman Soucek earned his doctoral degree from the Friedrich-Alexander University Erlangen-Nürnberg, Germany. Currently, he is a research associate at the Chair of Psychology, especially Organizational and Social Psychology, at the Friedrich-Alexander University Erlangen-Nürnberg. His research interests include resilience in the workplace, personnel development, evaluation of training interventions, and organizational behavior (escalation of commitment and ethical decision-making). He is a member of the Academy of Management, European Association of Work and Organizational Psychology, and German Psychological Association. His leisure activities include cycling and bouldering.

Klaus Moser studied psychology and philosophy of sciences at the University of Mannheim, Germany, and completed his diploma (comparable to a master's degree) in 1986. From 1986 until 1995, he was a research and teaching assistant at University of Hohenheim, Germany, where he completed his dissertation in 1989. From 1995 to 1998, he was the director of the institute of work and organizational psychology at the Justus-Liebig-Universität Gießen, and since 1998, he is the professor for industrial/organizational and social psychology at the FriedrichAlexander University of Erlangen-Nürnberg, Germany. His current research interests are personnel selection and performance appraisal, training and career development, organizational commitment, unemployment, and meaning of work. He also volunteers for a liberal scholarship foundation and plays chess. 